\title{
Espectroscopia de Ressonância Magnética Nuclear em Medicina
}

\author{
LIONELLO POGLIANI*
}

Na primeira parte deste artigo trata-se da ressonância magnética nuclear (NMR) in vivo, e na segunda da NMR Imaging. Na primeira parte, para além dos conceitos de base da NMR, resumem-se alguns conceitos $e$ estudos da espectroscopia de ressonância magnética nuclear in vivo, mais conhecida na literatura médica como espectroscopia de ressonância magnética, MR ou MR in vivo. Embora menos conhecida do que a NMR este tipo de espectroscopia permitiu demonstrar que alguns importantes processos moleculares bioquímicos podem ser evidenciados em vivo, seja em situação normal seja em situação patológica. Na segunda parte referemse alguns estudos NMR in vitro, estudos que foram fundamentais para 0 desenvolvimento das técnicas in vivo, e especialmente da NMiR imaging também conhecida na literatura como zeugmatografia, spin imaging, Tomografia NMR e FONAR (field focused nuclear magnetic resonance). A NMR Imaging permite hoje produzir imagens do interior do corpo humano ou de qualquer material biológico, e em alguns casos mesmo de materiais não biológicos, sendo a qualidade das imagens obtidas comparável com a das imagens obtidas pela Tomografia de raios $\mathrm{X}$.

\section{MR in vivo ELEMENTOS DE RMN}

Para a espectroscopia NMR são necessários campos magnéticos de cerca $1,5 \mathrm{~T}$ ( $1 \mathrm{~T}=1$ tesla $=10^{4}$ gauss $)$, e uma homogeneidade de campo magnético de cerca de 0,5 ppm (partes por milhão) sobre 0 volume total de substância analisada. Para compreender a NMR das radiofrequências), sendo a condição de ressonância:

$$
\omega=2 \pi v=\gamma B_{\text {eff }}
$$

onde $\omega$ é a frequência de Larmor, $\gamma$ é a constante magnetogírica, que é uma propriedade nuclear (cada tipo de núcleo tem um valor de $\gamma$ diferente) e $B_{\text {eff }}$ é 0 campo magnético efectivo a nivel nuclear, geralmente diferente de $B$ de algumas partes por milhão $\left(B_{\text {eff }}=B_{e}+B_{l o c}: B_{e}=\right.$ campo magnético externo devido ao magneto e $B_{10 c}=$ campo magnético local devido ao núcleo). Essa diferença é devida à influência da estrutura molecular em volta do núcleo observado, funcionando essa estrutura como uma espécie de filtro do campo magnético $B$ na vizinhança do núcleo e por conseguinte cada núcleo, numa molécula, que possui uma estrutura molecular diferente em volta de si, experimenta um $\mathrm{B}_{\text {eff }}$ diferente. As energias usadas em ressonância magnética são muito pequenas, cerca de $10^{-10}$ das energias usadas nos raios $\mathrm{X}, 0$ que, do ponto de vista médico, implica que a técnica MR ou NMR Imaging seja muito menos perigosa para um organismo vivo, que uma técnica médica baseada nos raios $X$, como a TAC (tomografia axial computadorizada).

Da eq. 1 é evidente que cada núcleo de fósforo do ATP entrará em ressonância a uma frequência diferente (diferenças da ordem de $20 \mu \mathrm{T}$ num campo magnético de 2 T) devido ao facto de sentir um $B_{\text {eff }}$ diferente. Essa diferença pode ser medida numa escala de frequências, chamada a escala em deslocamento químico (chemical shifts), construída escolhendo uma $v^{\star}$ padrão de um núcleo de uma molécula padrão (exemplo: núcleo do fósforo de um composto fosfórico para analisar um espectro de diferentes compostos fosfóricos) e fazendo a diferença entre 0 sinal a medir e o sinal padrão.

Uma escala em frequências, isto é em $\mathrm{Hz}$ (hertz), apresenta porém, a desvantagem de ser dependente da frequência do instrumento, isto é, do seu campo magnético aplicado: um núcleo medido em espectrómetros com campos magnéticos diferentes entra em ressonância a frequências diferentes o que põe a necessidade de uma escala em desloca- mento químico absoluta, independente da frequência $v$ "do instrumento, para se poder analisar espectros NMR obtidos a campos diferentes (nem todos os centros de pesquisa possuem a mesma aparelhagem NMR, pelo contrário, a variedade de espectrómetros é muito ampla: de 60 a 600 MHz em termos de ressonância do núcleo do hidrogénio, correspondentes a campos de 1,5 a 15 T aproximadamente). Essa escala absoluta de deslocamento químicos é medida em partes por milhão (ppm) e é assim definida:

$$
\delta(p p m)=\left[\left(v-v^{\prime}\right) / v^{\prime \prime}\right] 10^{6}
$$

Num espectro NMR $v>v^{\prime}$ se 0 pico do núcleo a analisar estiver à esquerda do pico do núcleo padrão.

$\mathrm{Na} \quad$ apresenta-se a estrutura de base de um espectro Nivin de três diferentes núcleos $\mathrm{A}, \mathrm{B}$ e C (em alta resolução, geralmente sinónimo de núcleos analisados em fase liquida a baixa viscosidade, e com campos magnéticos muito homogéneos)

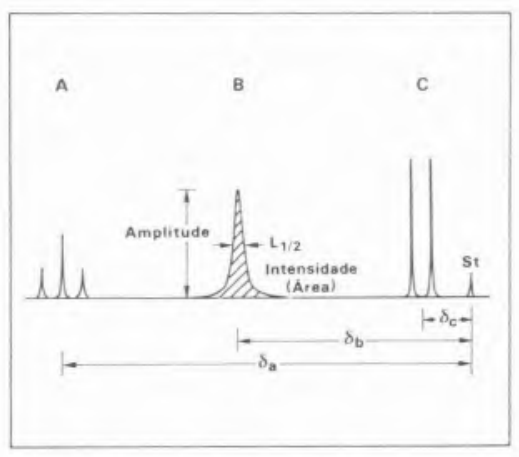

Figura 1: parâmetros fundamentais de um espectro NMR de alta resolução

0 deslocamento químico $\delta \mathrm{a}, \delta \mathrm{b}$ e $\delta c$, dos três picos $A, B$ e $C$ é dado pelo baricentro de cada pico (ou conjunto de picos, como em A e C). A estrutura dos picos dos núcleos $A$ (três picos) e C (2 picos), é devida a interacção destes dois núcleos com outros núcleos na molécula, ou entre eles mesmos. Em espectros RM de sistemas biológicos, geralmente em baixa resolução $\left(\mathrm{L}_{1 / 2}\right.$ grande, devido à inomogeneidade do campo magnético no largo espaço entre os dois pólos magnéti- 
cos para permitir a entrada de um animal ou mesmo de uma pessoa, e também devido à inomogeneidade do material analisado), essa estrutura desaparece devido à $L_{1 / 2}$ a meia altura do pico nuclear. Na realidade, um espectro RM parece-se mais com um conjunto de picos de tipo B.

A área (intensidade do pico) de um pico NMR, é proporcional ao número de núcleos equivalentes que contribuem na sua formação, e assim,conhecendo a quantidade de núcleos que formam um certo pico de ressonância, pode-se determinar, em princípio, pela simples confrontação da intensidade dos picos, a quantidade dos outros núcleos, e se existirem moléculas diferentes no sistema examinado (por exemplo, diferentes compostos fosfóricos: ATP, ADP, NADP, NADPH, PCr, G-6-P, F-1,6-P, etc..) determina-se a quantidade das diferentes espécies moleculares (é sempre possivel introduzir no sistema uma quantidade padrão e determinar as outras quantidades relativamente a essa).

Outros dois parâmetros, não directamente explicitados na figura 1 são os tempos de relaxação $T_{1}$ spin-rede e $T_{2}$ spin-spin. 0 spin nuclear I, é a propriedade do núcleo se orientar no campo magnético. Exemplo prático: assimilando o comportamento do spin nuclear ao comportamento da agulha de uma bússola no campo magnético terrestre, percebemos que existe uma posição mais favorável (paralela ao campo magnético) e uma menos favorável (antiparalela ao mesmo campo) e por conseguinte ela possui dois valores extremos direcionalmente opostos relativamente ao campo magnético terrestre, e se dermos ao estado inicial (paralelo) 0 valor I 0 outro estado (estado final ou excitado) terá 0 valor -I (antiparalelo). Esses dois tempos podem influir sobre a intensidade (relaxação spin-rede) e a largura a meia altura do pico (relaxação spin-spin). Após a absorção num sistema nuclear, em condição de ressonância, este acha-se, num estado excitado, e então o sistema, fora da ressonância, dissipa 0 excesso de energia por meio de processos não radiativos voltando ao equilibrio inicial (a agulha da bússola constrangida magneticamente por um forte magneto artificial externo ao estado -I volta, uma vez eliminado o magneto artificial, ao estado I num tempo que é característico da estrutura do mecanismo da bússola) por meio dos processos de relaxação.
0 processo de relaxação que controla 0 retorno do sistema de spins nucleares ao estado de equilibrio inicial com devolução do excesso da energia ao sistema circundante, sob forma de calor, é chamado relaxação spin-rede e caracterizado por um tempo $\mathrm{T}_{1}$, que geralmente vai de 0,1 a 10 segundos. Os tempos de relaxação spin-rede, podem dar importantes informações sobre sistemas bioquímicos (assim como o retorno ao equilibrio da agulha da bússola, nos pode dar uma ideia da qualidade do mecanismo da mesma bússola), como veremos no fim deste artigo. 0 tempo de relaxação spin-spin $T_{2}$, que é ou menor ou igual ao tempo de relaxação spinrede, é o tempo que caracteriza a permuta de energia no interior do mesmo sistema de spin nucleares, uma vez fora de ressonância. Voltando ao exemplo da bússola, podemos dizer que se trabalhamos com muitas bússolas (sobretudo se com características magnéticas e mecânicas diferentes) todas muito próximas e todas no estado $-\mathrm{I}$, o retorno ao estado de equilíbrio I (todas alinhadas com 0 do campo magnético terrestre) será influenciada pelas interacções relativas das agulhas, e claramente 0 tempo que governa estas interacções nunca poderá ser maior (no máximo será igual) ao tempo de retorno ao equilíbrio inicial I da bússola isolada.

\section{CARACTERÍSTICAS DA RM IN VIVO}

Os dois seguintes núcleos tornaram-se os mais importantes nas pesquisas RM de tipo biológico: $\mathrm{H}-1$ $(99,98 / 100)$ e P-31 $(100 / 6,63)$. Outros isótopos nucleares como, por exemplo, 0 C-13(1,59/1,11), muito usado na química orgânica, tiveram um menor impacto devido à baixa abundância natural (primeiro número em parêntesis) e sensibilidade relativa (com campo magnético constante para um igual número de núcleos: segundo número em parêntesis); 0 isótopo nuclear mais abundante do carbono, o C-12(98,41/0), não possui propriedades magnéticas e por conseguinte é completamente insensivel a um campo magnético. A grande sensibilidade e abundância da água nos sistemas biológicos e por conseguinte do seus hidrogénios $\mathrm{H}-1$, foram a causa do grande desenvolvimento médico-diagnóstico da técnica NMR Imaging, que é essencialmente aplicada aos hidrogénios da água.
Em RM, além do $\mathrm{H}-1,0$ núcleo mais importante foi o P-31 [5-16]. Essa técnica, permitiu realizar um mapa dos compostos mais importantes do fósforo dos diferentes orgãos de muitos animais, ou em condições naturais patológicas. Os metabolitos fosfóricos, além de terem uma i) importância fundamental no equilíbrio energético dos organismos vivos, ii) estão geralmente dissolvidos nos fluidos biológicos e iii) apresentam uma variedade limitada nos organismos biológicos sendo o número de núcleos do fósforo iv) em cada um deles ainda mais limitada, facto que permite uma boa análise dos diferentes compostos fosfóricos presentes num organismo vivo (os factores ii, iii e iv contribuem para a existência de bons sinais NMR do P-31 de estes compostos).

Na figura 2 apresenta-se uma série de espectros RM P-31 (magneto de 5,7 T) do a) rim, b) coração e c) fígado de rato. Para obter esses espectros 0 correspondente rato narcotisado, é posicionado de maneira a que 0 orgão a analisar, se encontre no centro da cavidade magnética (tarefa geralmente complicada) onde o campo é mais homogéneo, e sobre 0 'situ' (daqui outros dois acrónimos para esse tipo de NMR: topical MR, TMR ou in situ MR ) de interesse do rato é posto 0 circuito transmissor-receptor (de 2 a $0.5 \mathrm{~cm}$ de raio).

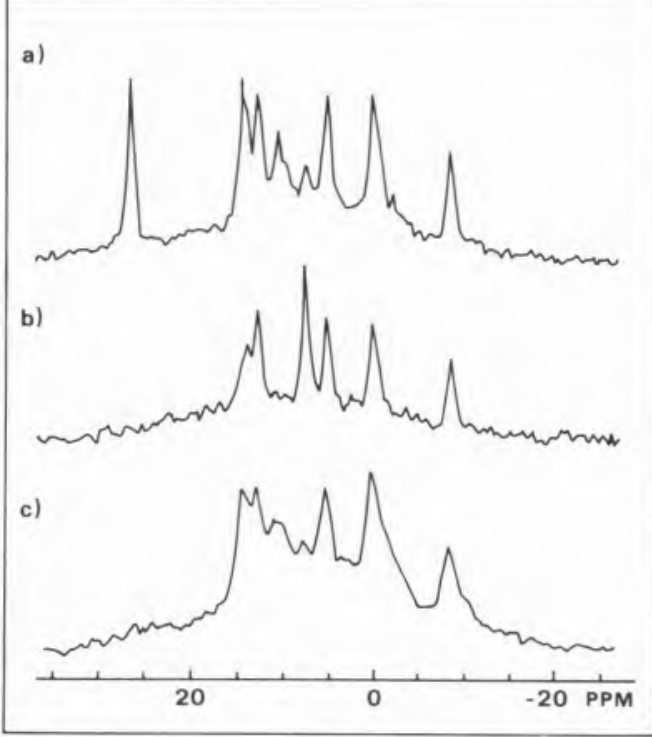

Figura 2: Espectro RM (P-31) de a) rim, b) coração e c) fígado de rato (explicaçāo no texto)

Os sinais da figura 2 são da direita para a esquerda: os picos dos núcleos de fósforo, (pico padrão) e do ATP, o 
pico da fosfocreatina ( $\mathrm{PCr}$, geralmente utilizado como padrão na deslocamento químico) muito pequeno em a) e c), em a) um pico do fosfato inorgânico (Pi) na urina, em c) dois picos pequenos mal resolvidos de dois fosfodiésteres (PD), em a), b) e c) um pico do Pi intracelular e um pico de um monofosfato $\mathrm{mP}$ (geralmente açúcar fosforilado), em b) e c) esses dois últimos picos estão muito próximos um do outro. Em c) na parte esquerda do pico do ATP nota-se um alargamento devido aos picos do $\mathrm{NAD}+\mathrm{NADH}$, cujo deslocamento químico é muito semelhante ao deslocamento químico do ATP, o mesmo ocorrendo com os dois picos do ADP. 0 espectro $\mathrm{P}-31$ do cérebro de rato é muito parecido com 0 espectro b), também com altas percentagens de $\mathrm{PCr}$. 0 ultimo pico em a) é 0 do ácido dimetilfosfónico, usado como padrão externo (achando-se num microrecipiente externo ao crânio) para determinar a quantidade de fósforo dos outros picos. 0 pico do PD em c) serviu para confirmar a existência de elevadas quantidades de fosfodiésteres em certos tecidos (quantidade até então subestimada). Os fósforos de DNA, RNA e fosfolipidos não aparecem devido ao facto de esses sinais serem demasiado largos e pequenos na altura. 0 pico dos fosfodiésteres PD nos músculos pertencem à glicerofosfocolina, e glicerofosfoetanolamina e foram identificados como produtos de degradação de membranas fosfolipidicas. No músculo distrófico, perto desse dois picos, aparece um terceiro pico de um outro $\mathrm{PD}$, que pela análise do deslocamento químico, foi identificado como 0 pico devido à L-serina etanolamina fosfodiéster.

0 deslocamento químico do sinal do Pi é geralmente utilizado para determinar de maneira não invasiva $0 \mathrm{pH}$ intra-celular. Aos valores de $\mathrm{pH}$ biológico existem duas espécies de fosfatos, em rápido equilíbrio:

$$
\mathrm{HPO}_{4}^{2-}+\mathrm{H}^{+} \rightleftarrows \mathrm{H}_{2} \mathrm{PO}_{4}^{-}
$$

Sendo o equilibrio entre essas duas espécies muito rápido, é possivel ver um só sinal (sinal médio), cujo deslocamento químico (dependendo da $\%$ dos dois fosfatos presentes), varia segundo $0 \mathrm{pH}$, podendo a variação chegar a ser de 2-2,5 ppm, de maneira que $0 \mathrm{pH}$ intracelular pode ser determinado medindo o deslocamento químico do $\mathrm{Pi}$ relativamente a um pico padrão cujo deslocamento quimico é constante ao variar $0 \mathrm{pH}$ (geralmente 0 pico do $\mathrm{PCr}$ ). 0 conhecimento do deslocamento químico do $\mathrm{Pi}$, e por conseguinte do $\mathrm{pH}$ em diferentes partes dos tecidos biológicos, é um modo de reconhecer os diferentes compartimentos desses mesmos tecidos. Um caso muito simples de compartimentação é visivel no espectro do rim da figura $2 \mathrm{a}$, onde temos um pico do $\mathrm{Pi}$ da urina, e à sua esquerda 0 pico maior, de $\mathrm{Pi}$ intracelular; o $\mathrm{Pi}$ da urina acha-se por conseguinte num compartimento diferente, e mais ácido do rim.

Os iões metálicos também influenciam o deslocamento químico dos núcleos com os quais interactuam: quando o ATP interactua com o catião $\mathrm{Mg}$, por exemplo, o pico P do ATP desloca-se 1,7 ppm para as altas frequências relativamente ao mesmo pico do ATP sem Mg ; 0 deslocamento químico desse pico, que é observado na sistemas biológicos, diz-nos que $95 \%$ do ATP está complexado com 0 catião do $\mathrm{Mg}$.

Espectros P-31 in vivo do figado $\mathrm{e}$ dos rins de cobaias, mostraram claramente que depois das cobaias terem ingerido frutose, 0 nivel de ATP e de Pi diminuía e aumentava 0 nivel de $\mathrm{mP}$ (fosfomonoéster: um açúcar fosforilado). Esta observação conduz-nos directamente a um dos usos mais frequentes da RM em vivo: seguir a variação da concentração dos metabólitos no tempo (a resolução temporal de um uma experiência $\mathrm{RM}(\mathrm{P}-31)$ é de cerca 3 minutos) em função do estado fisiológico da cobaias. A figura 3 apresenta três séries de espectros $\mathrm{RM}(\mathrm{P}-31)$ do cérebro de um rato sujeito, de hora a hora, a três episódios reversiveis de uma mesma diminuição da pressão arterial do oxigénio (hipoxia), diminuida de $12 \%$ do nivel normal, sendo a pressão arterial global mantida durante esse periodo por meio de infusões intravenosas de epinefrina).

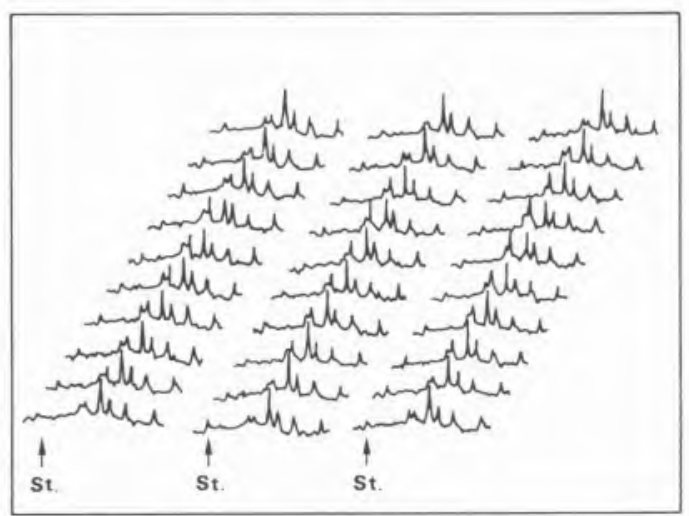

0 primeiro espectro de cada série espectro padrão, foi tomado a nível normal de $p\left(\mathrm{O}_{2}\right)$, sendo os outros espectros feitos cada 5 minutos (os 5 espectros sucessivos na cada série; 0 sétimo é traçado a $45 \mathrm{~min}$ ) em condições de hipoxia, aos 45 min os niveis normais de $p\left(\mathrm{O}_{2}\right)$ foram restabelecidos (últimos três espectros). Os picos são os mesmos da figura $2 \mathrm{~b}$, com um pequeno pico padrão à esquerda de cada série, e as variações que se notam ao nivel de cada pico reflectem 0 estado metabólico do cérebro quando sujeito ao estado patológico: relativa constância dos picos do ATP e PCr. consistente aumento do pico do $\mathrm{mP}$ e especialmente do pico do Pi cujo deslocamento químico varia (avizinhando-se do $\mathrm{PCr}$ ) indicando, assim, uma acidose dos tecidos cerebrais lesionados (com efeito $0 \mathrm{pH}$ varia de 7,4 a 6,5 ). 0 s espectros indicam-nos, também, que o fenómeno é perfeitamente reversivel, pois eliminada a hipoxia os espectros voltam a ser normais, isto é, o metabolismo do cérebro retorna ao estado normal. A constância ou variação dos diferentes picos é uma característica do tipo de patologia, por exemplo, uma pancada mecânica no cérebro causa abaixamento dos picos do ATP e PCr e aumento dos picos do $\mathrm{mP}$ e sobretudo do $\mathrm{Pi}$, e às vezes a recuperação parece seguir um mecanismo oscilatório (note-se a importância desse último tipo de pesquisa para a indústria de automóveis: a General Motors, GM, instituiu em 1985 um prémio para o melhor trabalho sobre o metabolismo do cérebro, logo depois de ter sofrido um golpe mecânico capaz de simular o que se passava durante um acidente de automóvel). Essas e outras experiências RM demonstram como é possivel seguir a actividade metabólica de diferentes partes do corpo (mesmo muito pequenas) em directo, sem fazer recurso à analise bioquímica dos tecidos do paciente, e de seguir. também, em directo 0 efeito de fármacos. Trabalhos deste tipo geralmente necessitam de uma equipa constituída a médicos (cirurgiões e anestesistas). espectroscopistas, bioquímicos, engenheiros electrónicos e às vezes também mecânicos.

Figura 3: Espectros RM(P-31) de cérebro de rato sujeito a condiçōes reversiveis de hipoxia. 
Os espectros $\mathrm{RM}(\mathrm{H}-1)$ em vivo $[17,18]$ são geralmente a) dominados pelo grande pico dos $\mathrm{H}-1$ da água, que cobre muitos picos importantes e b) constituidos de uma grande quantidade de picos que se recobrem, parcialmente, uns aos outros. Com técnicas especiais é possivel reduzir a intensidade do pico da água e, além disso, às vezes, é possivel ver picos de substâncias presentes em quantidades semelhantes à da água, por exemplo, um músculo com distrofia de Duchenne apresenta um sinal da água mais pequeno e um sinal dos $\mathrm{H}-1$ lipidi$\cos$ maior que um músculo normal. Enriquecendo em C-13 certos compostos é possível seguir em directo, por meio da $\mathrm{RM}(\mathrm{C}-13)[19,20]$, o metabolismo dessas substâncias nos sistemas biológicos, esta última técnica oferecendo a vantagem da grande gama de deslocamento químicos do $\mathrm{C}-13$ (com a vantagem de sinais bem separados), e do maior número de compostos que é possivel estudar.

Antes de terminar este capítulo algumas palavras sobre um espectrómetro para estudos RM em vivo de pequenos animais e extremidades do corpo humano. Trata-se de um espectrómetro com magneto supercondutor (criomagneto) de He líquido (4K) com cavidade horizontal (figura 4). 0 diâmetro da cavidade horizontal pode variar de $15 \mathrm{~cm}$ a $60 \mathrm{~cm}$ (quanto maior é o diâmetro, menor é a resolução e a intensidade do campo: para $\mathrm{d}=15 \mathrm{~cm}$ podemos ter uma intensidade de campo magnético de 4,7 $T$, enquanto que para $d=60 \mathrm{~cm}$ podemos ter no máximo $\mathrm{B}=2 \mathrm{~T}$ )

Figura 4: Criomagneto com cavidade horizonta para estudos de RM em vivo

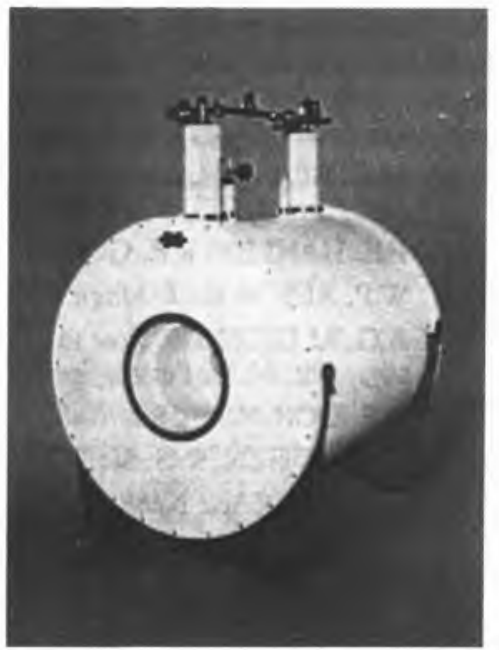

\section{N M R IN VITRO}

A NMR para aplicações médicas (in vitro) desenvolveu-se nos fins dos anos 60 ao longo dos anos 70 , e foi essencialmente $\mathrm{NMR}(\mathrm{H}-1)$ [21-30] e geralmente NMR do $\mathrm{H}-1$ da água de extractos biológi$\cos$, estudados em tubos de vidro (de 0,5$1,5 \mathrm{~cm}$ de diâmetro), de onde resulta 0 nome in vitro. Esses estudos foram fundamentais para o sucessivo desenvolvimento das técnicas NMR em vivo e especialmente da técnica NMR imaging. Eram geralmente estudos dos tempos de relaxação, sobretudo do tempo de relaxação spin-rede, quer pela maior facilidade e versatilidade experimental que apresentava a medida desse parâmetro, quer pelo seu maior poder diagnóstico, embora o tempo de relaxação spin-spin acabasse, também, posteriormente, por afirmar-se como importante parâmetro médico-diagnóstico. Embora esses dois tempos influenciem a altura e a largura de um sinal NMR, eles medem-se por meio de técnicas específicas pulsadas, que permitem seguir (em função do tempo) o retorno do sistema de spin nucleares ao equilibrio inicial. Voltemos ao exemplo prático da bússola: a agulha da bússola, imaginada como momento magnético, durante 0 retorno do estado -I ao estado I, pode-se decompor vectorialmente em duas componentes: uma longitudinal (ao longo do campo magnético terrestre) e a outra transversal (perpendicular a esse mesmo campo) o mesmo se podendo dizer do sistema de spin nucleares e, de facto, os dois tempos chamam-se também, spin-rede ou longitudinal, e spin-spin ou transversal. Para conhecer a evolução temporal dessa duas componentes (os dois tempos de relaxação seguem uma cinética de $1^{\text {a }}$ ordem, com variação exponencial e com $k=1 / T_{i}, i=1,2$ ), faz-se entrar em ressonância 0 sistema de spin nucleares a tempos diferentes, durante a fase de relaxação e mede-se a cada tempo a intensidade do sinal resultante, que será proporcional a uma das duas componentes.

Vamos examinar agora alguns valores do tempo de relaxação spin-rede (em segundos) dos $\mathrm{H}-1$ da água de alguns extractos biológicos de tecidos sãos e cancerosos (erro associado de ca. $10 \%$ ):
A partir destes valores é evidente a possibilidade de diferenciar diferentes tecidos biológicos e, ainda mais importante, de diferenciar patologicamente 0 mesmo tecido por meio de medidas de relaxação spin-rede. Vejamos agora outros valores dos tempos de relaxação spin-rede (sr) e spin-spin (ss) de tecidos normais de pacientes normais (normnorm) e pacientes com cancro (normcanc):

\begin{tabular}{lrcc}
\hline & normal & grávida & cancro \\
\hline tempo spin-rede & 0,27 & 0,37 & \multicolumn{1}{c}{0,72} \\
tempo spin-spin & 0,084 & 0,047 & 0,098 \\
$\%$ de água & 27 & 34 & 75 \\
\hline
\end{tabular}

Neste segundo caso a possibilidade de diferenciar tecidos normais de pacientes patologicamente diferentes é muito mais problemática; o tempo de relaxação é uma característica específica do 'situ' e, por conseguinte, só é possível isolar de maneira clara o local cancerígeno pelo seu valor específico do tempo de relaxação. A diferença nos valores do tempo de relaxação spin-rede dos pulmões norm-norm $(0,54)$ e normal $(0,79$; veja-se valores precedentes) leva-nos a discutir um dos grandes problemas da técnica in vitro: o problema da extracção e preparação dos extractos biológicos. 0 tempo de relaxação pode variar dramaticamente, segundo o método usado para extrair e preparar o tecido: extracção a frio ou a quente, tempo e tipo de armazenamento, conservação a temperaturas diferentes e em ambientes secos ou húmidos, ricos em oxigénio ou em azoto, tipo de solvente e tampão usado, a viscosidade do preparado, $0 \mathrm{pH}$ e a força iónica e o tipo de iōes presentes; por exemplo, pequenas quantidades $(0,00001 \mathrm{M})$ de impurezas de iões paramagnéticos podem falsear completamente 0 valor do tempo de relaxação. Adiciona-se ainda um outro problema: a dificuldade de preparar muitos preparados perfeitamente iguais do mesmo tecido de um mesmo paciente, para obter médias significativas. A parte experimental da preparação biológica assumia uma importância dramática para esse tipo de medida e não era raro que de preparados aparentemente iguais, se obtivessem

\begin{tabular}{llllll}
\hline & Cólon & Pulmōes & Ovários & Cerviz & Miométrio \\
\hline norm-norm (sr/ss) & $0,42 / 0,048$ & $0,54 / 0,087$ & $0,50 / 0,059$ & $0,51 / 0,041$ & $0,55 / 0,066$ \\
norm-canc (sr/ss) & $0,6 / 0,091$ & $0,49 / 0,074$ & $0,61 / 0,060$ & $0,62 / 0,071$ & $0,51 / 0,054$ \\
\hline
\end{tabular}


tempos de relaxação completamente diferentes. Todos estes factos, claramente, marcam, desde 0 início, a necessidade de fazer medidas de relaxação em directo, isto é, em vivo, curto-circuitando assim todos esses problemas. Mas esqueçamos por agora essas dificuldades, esperando pela técnica NMR imaging, e vejamos se é possível diferenciar diferentes condições fisiológicas de um mesmo tecido e ver se é possivel relacionar 0 tempo de relaxação com a quantidade de água do sistema. Seja 0 caso da mama da rata i) normal, ii) grávida e iii) com cancro da mama. para qualquer amostra de tecido normal, e é geralmente independente da frequência (veja-se mais adiante), os tecidos com cancro apresentam um $\mathrm{MI} \sim 3$.

$$
\mathrm{MI}=\mathrm{T}_{1 \mathrm{i}} /\left\langle\mathrm{T}_{1}\right\rangle+\mathrm{T}_{2 \mathrm{i}} /\left\langle\mathrm{T}_{2}\right\rangle
$$

Foi sugerido que se usasse o $\mathrm{Ml}$ em vez da densidade da água, ou os tempos de relaxação, para desenvolver uma espécie de mapa ou imaging da malignidade (NMR - MI Imaging), mas essa sugestão nunca foi desenvolvida na prática.

Na verdade, 0 que parece influenciar o valor do tempo de relaxação [33-37],

\begin{tabular}{lccccccccr}
\hline & Mama & Pele & Músculo & Pulmōes & Esqueleto & Esófago & Estômago & Intestino & Figado \\
\hline normal & 0,37 & 0,62 & 1,02 & 0,79 & 0,55 & 0,80 & 0,76 & 0,64 & 0,57 \\
cancro & 1,08 & 1,05 & 1,41 & 1,11 & 1,03 & 1,04 & 1,24 & 1,12 & 0,83 \\
\hline
\end{tabular}

Analisando estes dados percebemos i) como utilizando dois tempos de relaxação em vez de um (0 mesmo discurso vale pelos dados precedentes) se pode diferenciar de maneira mais evidente os diferentes estados fisiológicos e ii) como os diferentes estados fisiológicos estão ligados a diferentes percentagens de água. Se pudéssemos, em princípio, fazer uma mapa da \% de água, ou dos tempos de relaxação, do corpo humano inteiro poderíamos obter informação sobre 0 estado de saúde das suas diferentes partes. $E$ baseando-se numa série de estudos semelhantes, foi apresentada a seguinte relação empírica aproximada entre a relaxação longitudinal (medida em s) e a densidade da água [31] (fractional water content: praticamente a \%)

$$
\rho=0,65+0,126 T_{1}
$$

cuja forma diferencial é

$$
\Delta \mathrm{T}_{1}=7,94 \Delta \mathrm{g}
$$

a qual nos diz claramente que pequenas variações no conteúdo de água podem ser a origem de grandes variações no tempo de relaxação longitudinal .

Baseando-se nos dados dos dois conjunto do mesmo tipo de tecidos normais. 0 valor de Ml é muito perto de 2 é um conjunto de factores, sendo a densidade da água o factor mais importante; um outro factor parecem ser alterações na estrutura macromolecular da célula, e além disso as variações no tempo de relaxação traduzem também outras patologias e não somente 0 cancro.

Que valores de campos magnéticos ou frequências (veja-se eq. 1) utilizar para esse tipo de estudo NMR? Na figura 5 vemos a resposta tempo de relaxação spin-spin é geralmente insensível à intensidade do campo magnético).

Conclui-se então que 0 que necessitamos é de um aparelho capaz de fornecer imagens do corpo como faz o TAC, mas que utilize campos magnéticos (em cuja abertura magnética possa entrar um corpo humano) e radiofrequências (menos perniciosas do que os raios $\mathrm{X}$ ), e cuja intensidade de imagem seja baseada sobre a diferente densidade de água ou diferentes valores da relaxação das diferentes partes de um corpo humano. Necessitamos também de alguém, que nos diga como codificar na equação de ressonância (eq. 1) 0 espaço, de maneira que as moléculas de água no elemento volumétrico dVi (aquilo que será 0 pixel, 'picture element', da imagem ou o voxel, 'volume element', ressonante) entrem em ressonância a uma frequência diferente das moléculas de água (ou mais geralmente de um núcleo I) no elemento volumétrico dVj (visualização em amplitude/espaço em vez que amplitude/frequência). $\mathrm{Na} \mathrm{RM}$ isso é conseguido mudando de lugar no interior do magneto ou o circuito transmissor-receptor ou o paciente, sendo que no interior da região detectada (determinada pelo raio do circuito)

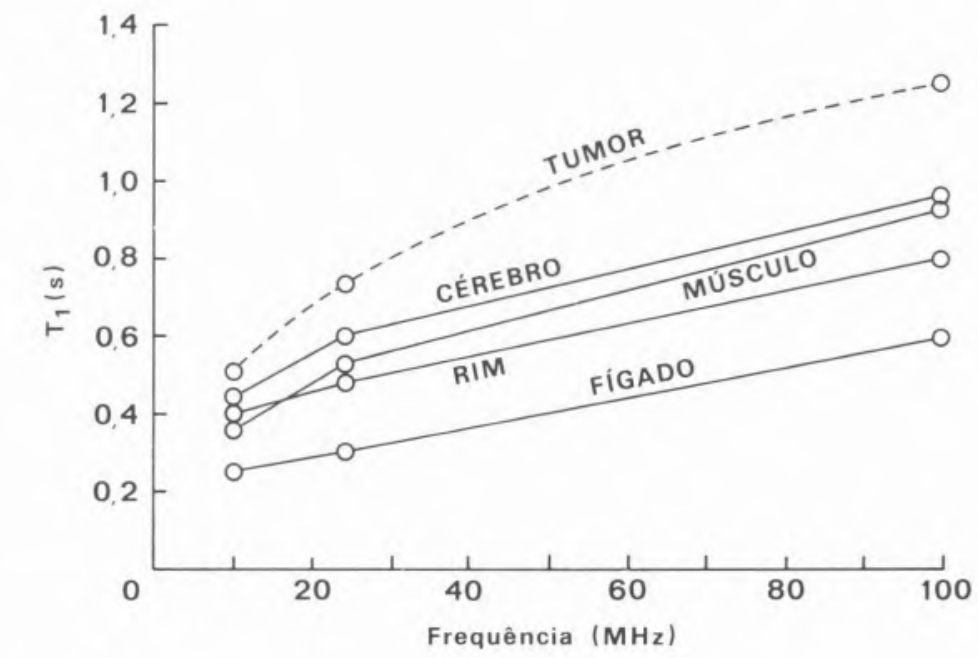

Figura 5: Tempos de relaxaçāo spin-rede "in vitro" da água de tecidos normais e patológicos em funçāo da frequência do aparelho utilizado.

Da figura 5 podemos concluir que altos campos magnéticos produzem, em geral (o músculo e o cérebro são excepções) uma melhor separação dos tempos de relaxação spin-rede (0 não é possivel uma visualização espacial. Claro que com isto a NMR imaging vai perder a informação em frequências, pois só é possivel ver a água e não, por exemplo, também os $\mathrm{H}-1$ dos lípidos, mas esse problema vai ser resolvido pela NMR Chemical Shift Imaging, a última novidade em NMR médico-diagnóstico. 


\section{N M R I M A G IN G ELEMENTOS DE NMR IMAGING}

A ideia e desenvolvimento prático da NMR Imaging (NMRI on MRI) foi levada a cabo por Paul C. Lauterbur [38], que a baptizou zeugmatografia (do grego zeugma = aquilo que se utiliza para unir), embora as bases matemáticas do problema da reconstrução de imagens a partir das suas projecçōes bidimensionais (que era uma parte do problema) fossem conhecidas desde 1917 [39], e tivessem sido aplicadas primeiramente em 1956 na astronomia [40], e depois noutros campos como microscópica electrónica e óptica. Os primeiros aparelhos NMR Imaging chegaram ao mercado médico no fim dos anos 70 , inicio anos 80 , e lembramos aqui que em 1972 foi anunciado [41] o primeiro EMI X-ray CT (computerized tomographic) vulgarmente conhecido como TAC. Voltemos ao NMR e imaginem-se ao dois tubos de NMR cheios de água num campo magnético não-homogéneo e cuja não-homogeneidade aumenta linearmente do pólo norte $\mathrm{N}$ ao pólo Sul S de um magneto (veja-se na figura 6 na parte superior 0 desenho bidimensional da experiência, e na parte inferior o resultado, isto é, o correspondente espectro NMR da água dos dois tubos): 0 resultado espectroscópico de uma experiência NMR feita deste modo só podem ser dois sinais diferentes dos dois volumes V1 e V2 de água, cujo deslocamento químico é um só, nos dois tubos, e isso porque a não-homogenidade do campo magnético, posiciona os volumes V1 e V2 em valores de campo magnético diferentes, e pela equação 1 a campos magnéticos diferentes correspondem frequências diferentes.
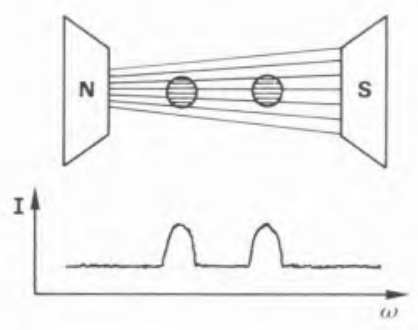

Figura 6: esquema do primeira experiência de zeugmatografia realizada por Paul C. Lauterbur.

Uma experiência de NMR assim projectada pode, então, ser utilizada para unir (zeugma) uma diversidade de frequências a uma diversidade de posicio- namentos espaciais de uma substância homogénea (desde que exista um só deslocamento químico). A não homogeneidade de campo magnético é realizada por meio de gradientes de campo magnético (gradientes de campo de pequena intensidade, denominados "shim coils", que aliás sempre existiram nos magnetos de NMR, sendo utilizados para tornar ainda mais homogéneo o campo magnético entre os dois pólos magnéticos). Quantitativamente 0 exemplo da figura 6 pode ser assim explicado: seja $B_{\text {eff }}=\left(B_{e}\right.$ $+B_{\text {loc }}$ ) o campo magnético efectivo no núcleo e $\mathrm{G}_{z}$ a intensidade do gradiente de campo magnético na direcção $z$, então 0 campo magnético total no ponto de coordenada $z$ é, $B=B_{\text {eff }}+z G_{z}$ e a equação 1 transforma-se na

$$
\omega=\gamma\left(B_{\text {eff }}+z G_{z}\right)
$$

que nos indica claramente que a um valor de $z$ corresponde um e um só valor da frequência uma vez que $B_{\text {eff }}$ for constante. Desta maneira fica codificada somente a dimensão $z$ (como na figura 6). Para codificar um ponto $P(x, y, z)$ basta introduzir três gradientes $G_{x}, G_{y}$ e $\mathrm{G}_{\mathrm{z}} \mathrm{e}$ assim teremos $\mathrm{P}(\mathrm{x}, \mathrm{y}, \mathrm{z})$.

Os valores dos gradientes lineares variam de 5 a $10 \mathrm{mT} / \mathrm{m}$, e a sua intensidade deve, de qualquer modo ser superior à não homogeneidade do campo $\mathrm{B}_{\mathrm{e}} \mathrm{O}$ qual, na NMRI, pode ser escolhido entre 0,5 e $1,5 \mathrm{~T}$.

Se $B_{\text {eff }}$ não for constante $(\mathrm{H}$ com diferentes deslocamento químicos a examinar) podem-se dar duas possibilidades: i) 0 elevado gradiente $G$, usado normalmente em NMRI, pode destruir a diferença em deslocamento químico ou ii) se os gradientes não forem muitos elevados, é possivel reter a informação em deslocamento químico no elemento de volume escolhido, e temos aquilo, que é conhecida como a Chemical Shift Imaging (ainda em fase de aperfeiçoamento) cuja resolução, porém, continua a ser muito baixa. Os gradientes utilizados são adiabáticos, isso é, não provocam transições energéticas de spin nuclear, e podem ser estáticos ou variáveis (oscilantes) no tempo. Na verdade, o problema do "imaging" é um pouco mais complicado que a simples utilização de três gradientes, e isto é exemplificado na maneira como Lauterbur, resolveu o problema da reconstrução da imagem. Lauterbur trabalhando com técnicas NMR de onda contínua (CW) [38], utilizou 4 gradientes a $45^{\circ}$ um do outro no plano $x, z$ (vejam-se as setas por debaixo dos espectros na figura 7 a). As 4 imagens mono-dimensionais (em frequência), produzidas por esses 4 gradientes, eram utilizadas para reconstruir (veja-se os 4 espectros na figura 7 a), 0 zeugmatograma $x, z$ dos dois volumes de água (figura 7 b)

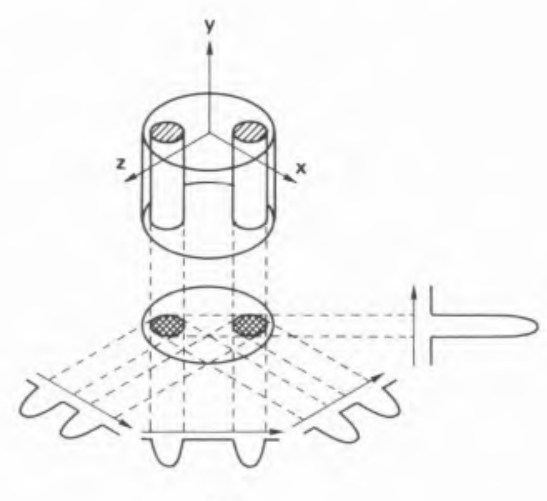

(a)

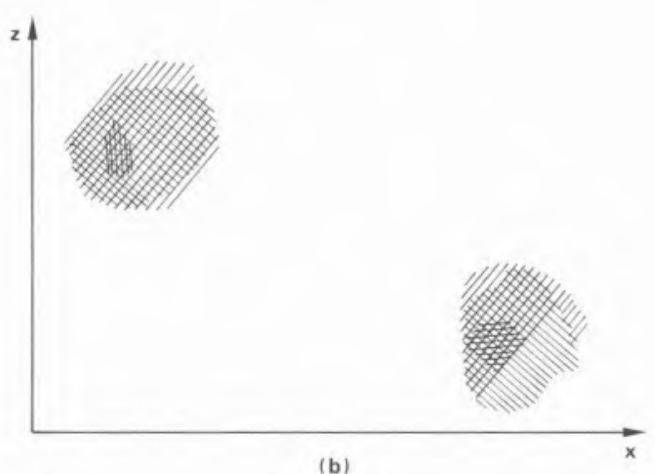

Figura 7: Reconstrução da imagem no experiência de Lauterbur [38], a) o objecto tridimensional, a sua projecção bidimensional paralelamente a y, e os 4 gradientes e as 4 projecçōes monodimensionais a $45^{\circ}$ uma da outra, b) o zeugmatograma dos dois volumes de água nos dois tubos de $-0,5 \mathrm{~cm}$ de diâmetro.

Se os primeiros métodos usados por Lauterbur utilizavam a onda contínua (o valor do campo externo $B_{e}$ é mantido constante e a frequência é variada de modo contínuo de maneira a fazer entrar em ressonância sequencialmente os diferentes núcleos), os métodos que se afirmaram posteriormente foram métodos pulsados (todos os núcleos entram em ressonância simultâneamente por meio de um forte impulso de alguns $\mu$ s e com utilização da Transformada de Fourier (para transformar o sinal resultante do impulso que é um sinal $\mathrm{S}_{t}=$ $\mathrm{S}$ (tempo, Intensidade) em $\mathrm{S}_{\mathrm{f}}=\mathrm{S}$ (frequência, Intensidade), que oferecem 
uma maior sensibilidade e versatilidade (sobretudo na obtenção e cálculo de imagens a partir do tempo de relaxação) [42-44]. A utilização conjunta de métodos pulsados, gradientes oscilantes e da FT permite usar diversos métodos de "imaging" que podem ser divididos em 4 classes segundo a geometria (disposição e estrutura dos gradientes e dos impulsos) usada para produzir o sinal NMR [45,46]: ponto, linha, plano e volume. Essa classificação é esquematizada na figura 8, a qual nos mostra, por exemplo que com o método do ponto sequencial é possivel receber informação de um só voxel a cada momento enquanto com o método planar (a zeugmatografia de Lauterbur era um método planar) obtemos informação de um plano inteiro de spins simultâneamente. $A$ vantagem do método pontual, cuja resolução é melhor, é que se trata de um método directo, isto é, um método que não precisa de uma máquina computadora para a elaboração prática da imagem. A ordem de grandeza de um voxel é de alguns $\mathrm{mm}^{3}$, e geralmente uma imagem é constituida de $256 \times 256$ pixels que necessitam de $\sim 64$ Kwords para a sua descrição de maneira que processar uma imagem de $256 \times 256 \times 256$ voxels não é uma tarefa simples.

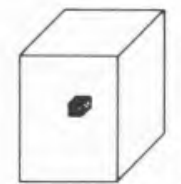

(a)

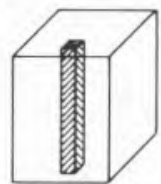

(b)

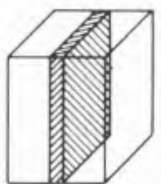

(c)

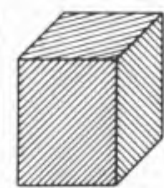

(d)
Figura 8: classificaçằo dos vários métodos de "imaging": a) método do ponto sequencial, b) método da linha sequencial, c) método do plano sequencial e d) método volumétrico.

Vejamos um pouco mais em detaIhe 0 método do ponto sequencial de Hinshaw [47], representado monodimensionalmente na figura 9. Hinshaw utiliza três gradientes lineares oscilantes ortogonais, causados por três bobinas dispostas ortogonalmente e percorridas por corrente alterna: 0 ponto de intersecção dos três gradientes é o ponto do qual obtemos um os pontos na volta desse ponto dão origem a sinais modulados em frequência que são facilmente filtrados. A posição do ponto sensivel é variada, variando sequencialmente os gradientes ortogonais sem necessidade de mexer o paciente na cavidade magnética.

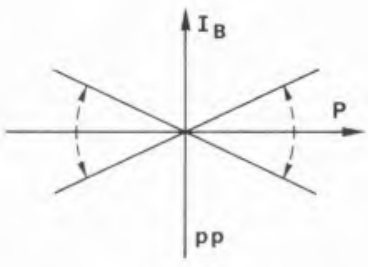

Figura 9: Localização do voxel por três gradientes oscilantes ortogonais, nesta imagem monodimensional um só gradiente oscilante localiza somente um plano.

Hinshaw, utiliza ainda uma série especial de impulsos, muito pouco espaçados entre eles que permitem definir a intensidade do sinal resultante Int como

$$
\text { Int }=k[\rho /(R+1)]
$$

onde $R=T_{1} / T_{2}$. Geralmente em líquidos pouco viscosos os dois tempos de relaxação são iguais de modo que Int = kp ( $k$ é uma constante de proporcionalidade), e a intensidade do sinal é proporcional à densidade dos spins, e no nosso caso dos $\mathrm{H}$ da água. Nas regiões onde a mobilidade da água é afectada de maneira que $T_{1} \gg T_{2}$ 0 sinal é dado por $\operatorname{lnt}=k(\rho / R)$.

A técnica "imaging" mais utilizada é a chamada "Spin-Echo Imaging" (existem diferentes variantes desta técnica) pela característica série de impulsos utilizada e que serve para medir os dois tempos de relaxação numa só experiência [42,48-51]. A intensidade In do sinal é

Int $=k \rho \exp \left(-T_{e} / T_{2}\right)\left[1-\exp \left(-T_{r} / T_{1}\right)\right]$

onde $\mathrm{T}_{\mathrm{e}}$ é o tempo de espera para a formação de um sinal de eco, resultante de um impulso eco (que maximiza de novo 0 sinal $S_{t}$ ), veja-se a figura 10), e $T_{r}$ pode ser visto como o tempo que o sinal demora para decair completamente a zero (geralmente $=5 \mathrm{~T}_{1}$ ) eco incluído (note-se na figura 10 que a impulsos de ecos sucessivos o maximo de $\mathrm{S}_{\mathrm{t}}$ é sempre menor).
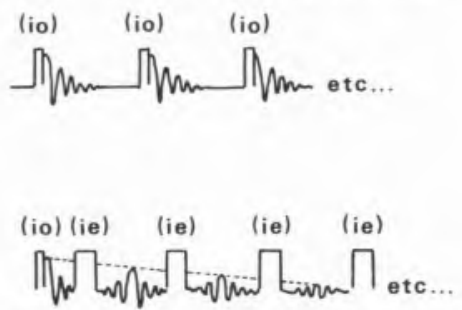

Figura 10: a) Série de impulsos de observação (io) do sinal NMR com os respectivos sinais $S(t, I)$ resultantes e b) uma série eco feita de um impulso (io) e de quatro impulso eco (ie) com os respectivos sinais ecos $\left(01^{0} \mathrm{de}\right.$ observação e os 3 sucessivos ecos de intensidade decrescente)
Os dois tempos $T_{e}$ e $T_{r}$ são tempos de acesso experimental e manipulando-os oportunamente podemos obter dois tipos de sinais "imaging" (no caso da eq. 7 a medida do sinal é feita depois do $1^{0}$ eco)

1) como $T_{r} \gg T_{1}$, obtemos imagens pesadas em $T_{2}$ :

$$
\text { Int }=k \rho \exp \left(-\mathrm{T}_{\mathrm{e}} / \mathrm{T}_{2}\right)
$$

e nesse caso para valores de tempos de relaxação spin-spin elevados a intensidade é máxima

2) como $T_{e} \ll T_{2}$, obtemos imagens pesadas em $T_{1}$ :

$$
\text { Int }=k \rho\left[1-\exp \left(-T_{r} / T_{1}\right)\right]
$$

e nesse caso para valores de tempos de relaxação longitudinal elevados, o sinal é minimo.

\section{CARACTERÍSTICAS DA NMR IMAGING}

A imagem NMR de um orgão humano ou animal, como apresentado no parágrafo precedente, depende quer da densidade de spin, no nosso caso dos $\mathrm{H}$ da água, quer dos valores dos tempos de relaxação da água, ao contrário da TAC com raios $X$, que depende somente do coeficiente de absorção da radiação $X$. É bom lembrar que a concentração da água no corpo humano pode variar, não somente com o nivel patológico do tecido, mas também com a dieta, a idade, 0 clima e os fármacos tomados.

Devido à dependência do sinal "imaging" do tempo de relaxação da água nos tecidos às vezes recorre-se à utilização de certos metais paramagnéticos como o $\mathrm{Mn}^{++}, \mathrm{Fe}^{3+}, \mathrm{Cu}^{++}, \mathrm{Ni}^{++}$, etc., como meio de contraste das imagens pois eles têm a propriedade de causar fortes variações negativas na relaxação longitudinal da água nos tecidos animais, de maneira que se torna muito importante para a MRI, o desenvolvimento de técnicas de síntese química de "carriers" de complexos metálicos paramagnéticos capazes de se localizar em certas partes do tecido, e aumentar assim o contraste com as outras partes. Vejamos por fim algumas imagens NMR [52-55]: na figura 11 está representada a região sagital do crânio, e em baixo um zoom da sua parte central obtida com 0 método spin-echo imaging. 

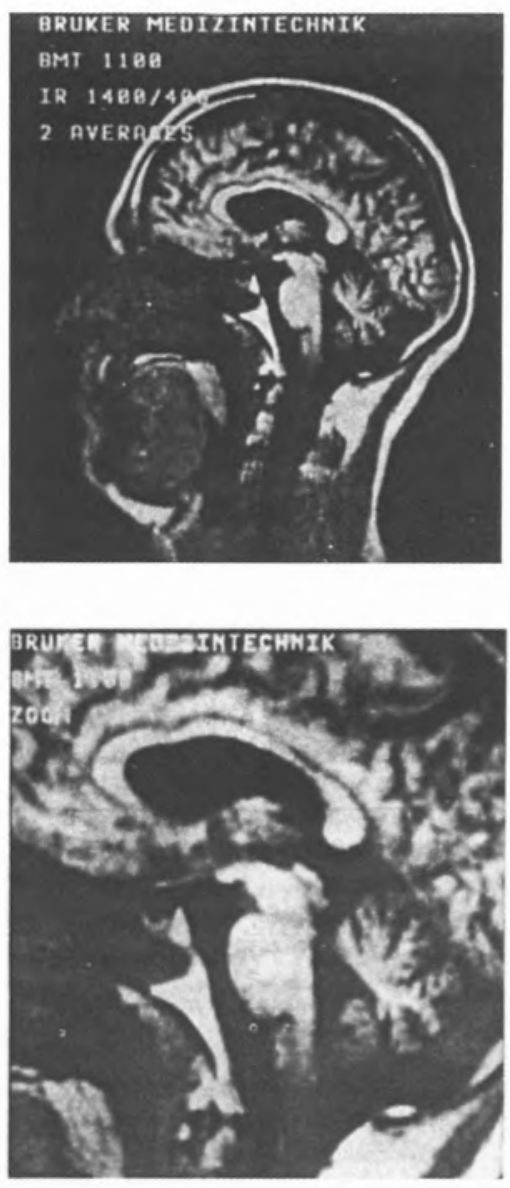

Figura 11: MRI da região sagital do crânio com um zoom da sua parte central, obtidos com um espectrómetro Bruker [54].

Com a mesma técnica foi obtida a série de 4 imagens de um meningioma frontal com edema em volta (parte branca central) do cérebro da figura 12. As quatro imagens diferentes são devidas a 4 ecos diferentes $\left(1^{\circ} \mathrm{eco}, 9^{\circ} \mathrm{eco}, 17^{\circ} \mathrm{e}\right.$ $25^{\circ}$ eco): veja-se como a cada eco corresponda um contraste diferente.

A região do tumor é de cerca $3 \mathrm{~cm}$ de diâmetro.

Figura 12: quatro "MRI spin-echo" (Bruker) [54] de um tumor do cérebro com edema em volta.
Na figura 13 vemos uma imagem eco de uma mulher grávida, segundo diferentes planos.

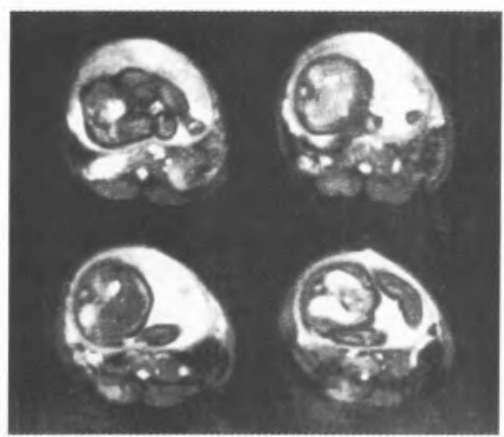

Figura 13: quatro imagens "NMR spin-eco" (Notingham machine) [53] de uma mulher grávida

Actualmente a tecnologia "NMR Imaging" permite obter imagens do $\mathrm{Na} \mathrm{e}$ do $\mathrm{P}$ de um organismo animal, mas não com a mesma resolução do hidrogénio da água. Tem sido objecto de debate a possibilidade de que os campos magnéticos, as radiofrequências e os gradientes de campo utilizados possam causar danos ao organismo humano ou animal em geral; ao nivel actual dos conheci- mentos esses danos (exceptuados os portadores de pace-maker) estão muito abaixo dos níveis estabelecidos de tolerabilidade. 0 único efeito detectado pelos pacientes tem sido um certo aquecimento dos tecidos analisados devido ao fenómeno de relaxação spin-rede. $\mathrm{Na}$ figura 14 é apresentado um exemplo de aparelho "NMR Imaging" Magneton da Siemens: o magneto é de tipo supercondutor de 0,5 T, os gradientes estão colocados na parte interna do magneto.

Antes de concluir este trabalho sobre a "NMRI" algumas considerações sobre a difusão e sobre a heterogeneidade dos tecidos biológicos serão apresentadas. Lembramos aqui que 0 uso de técnicas "NMR spin-echo" com gradientes de campo bem antes o desenvolvimento do NMRI era e continua a ser uma técnica bem estabelecida em estudos de difusão para medir o coeficiente de autodifusão translacional (translational selfdiffusion) $\mathrm{D}$, de núcleos móveis num campo magnético $[56,57]$. 0 sangue que flui nas veias e artérias é o responsável

\section{Figura 14: Aparelho NMR Imaging Magneton}

\section{Siemens [55]:}

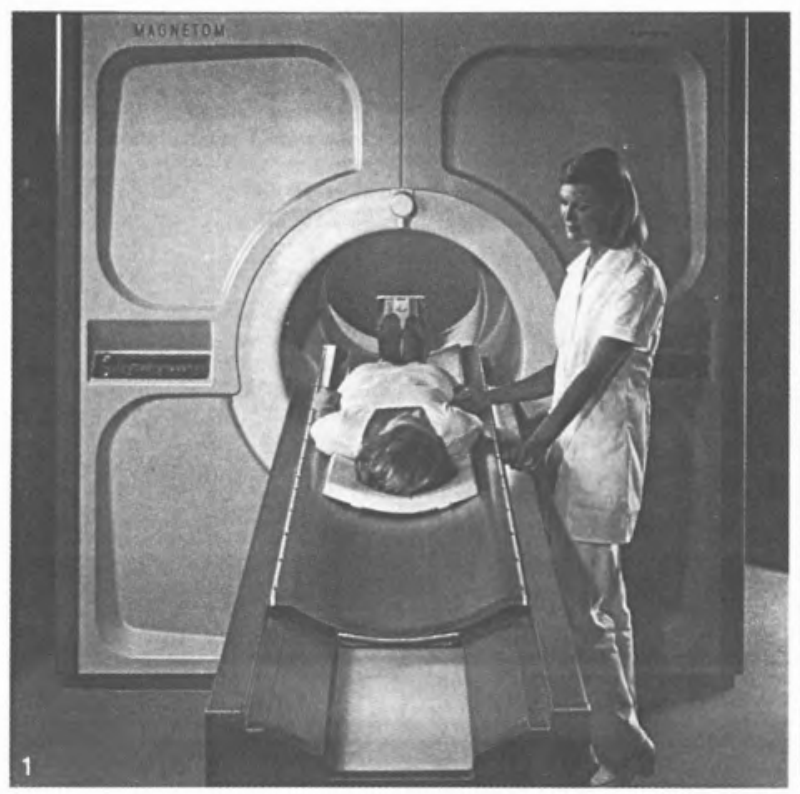

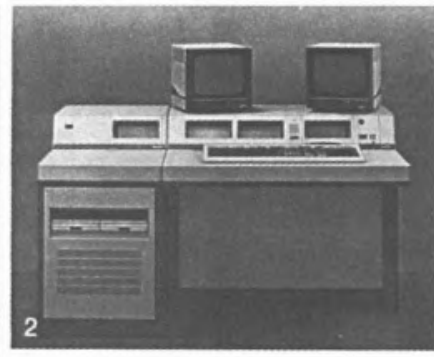

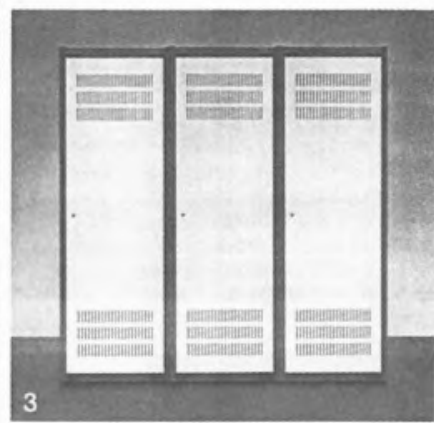

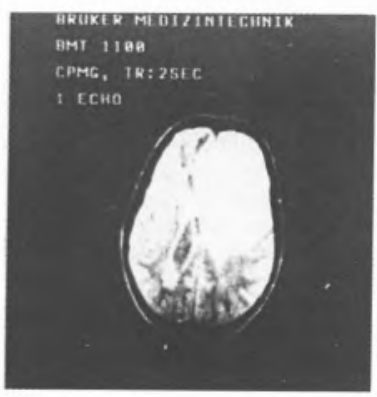
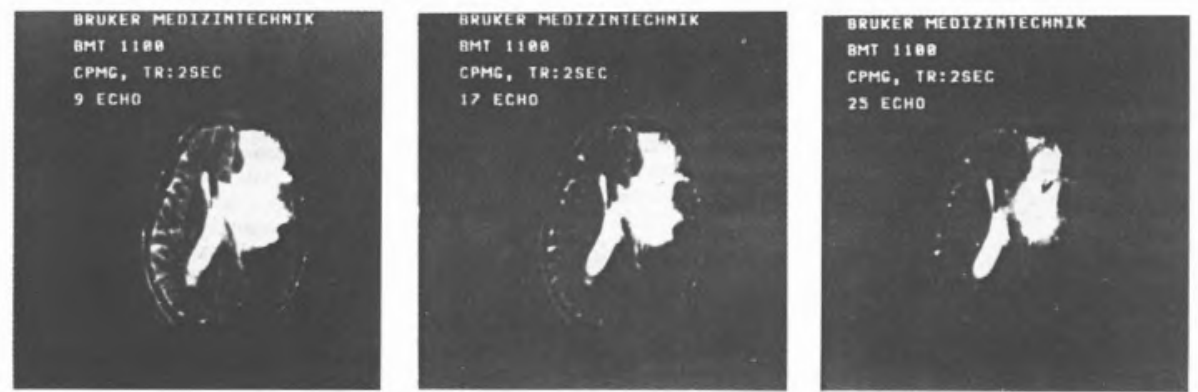
pela cor escura dessas partes dos tecidos, e 0 grau de escuridão (outras causas constantes) depende da velocidade do fluxo do sangue: se a velocidade for baixa não influencia a imagem, se pelo contrário a velocidade do sangue for elevada (isto é, se os spins da água do sangue depois de excitados tiverem tempo de sair do voxel antes de serem medidos e no momento da medida o voxel estiver ocupado por novos spins não excitados), então a intensidade do sinal desses novos spins não excitados, será praticamente nula e como as partes com mais água em "MRI" são as partes mais claras as partes sem água (isto é, sem água excitada) serão a parte mais escura.

A última consideração é sobre a heterogeneidade dos tecidos biológicos, que é a causa de uma heterogeneidade magnética (susceptibilidade magnética) dos mesmos tecidos, que pode assim vir a funcionar como um gradiente de campo interno ao próprio tecido [58]. Esses gradientes próprios não dão, porém, lugar a efeitos importantes nos campos magnéticos normais utilizados em "MRI", mas já com os campos mais altos que se utilizam para a "MRI" do fósforo esses efeitos passam a ser importantes, e alteram fortemente 0 contraste da imagem, sendo esta uma ulterior dificuldade para a "MRI" de núcleos que necessitam de campos magnéticos elevados.

\section{AGRADECIMENTOS}

Ao Eng $^{\circ}$ Eduardo Jorge N. Pereira pelo apoio técnico e linguístico oferecido ao longo da redacção deste artigo, e ao Professor Manuel J.E. Prieto pela detalhada análise científico-linguística do artigo.

\section{*Centro de Química Física Molecular IST, 1096 Lisboa Codex. \\ Em Licença sabática do Dipartimento di Chimica da UNICAL, 87030 Rende (CS), Itália.}

\section{BIBLIOGRAFIA}

1. T. L. James, Nuclear Magnetic Resonance in Biochemistry, Academic Press, New York, 1975.

2. D. G. Gadian, Nuclear Magnetic Resonance and its Applications to Living Systems, Clarendon, Oxford, 1982.

3. T.L. James, A. R. Margulis (editors), Biomedical Magnetic Resonance, Radiology Research and Educational Foundation, San Francisco, 1984.
4. T. L. James, W. M. Chew, D. D. Giannini, R. G. Mendez, M. E. Moseley, L. Pogliani, D. Vigneron, Applied Radiology 16 (1987) 40.

5. P. J. Seeley, S. J. W. Busby, D. G. Gadian, Biochem.Soc. Trans. 4 (1976) 62.

6. C. T. Burt, M. J. Danon, E. A. Millar, et al., Biophys.J. 21 (1978) 184a.

7. T. Brown, E. N. Chance, M. J. Dawson, et al., J.Physiol. (London) 267 (1980) 703.

8. R. G. T. Edwards, M. J. Dawson, D. R. Wilkie, et al., Lancet, 1 (1982) 725.

9. Y. Seo, M. Murakami, H. Watari et al., J.Biochem. 94 (1983) 729

10. A. P. Koretsky, S. Wang, J. Murphy-Boesch, Proc.Natl.Acad.Sci.USA 89 (1983) 7491.

11. L. Litt, R. G. Mendez, P. R. Weinstein,et al., Magn.Res.Med. 3 (1986) 619.

12. N. Ishige, L. H. Pitts, T. Hashimoto, L. Pogliani, M. Nishimura, GM Neural Trauma Research Award 1985.

13. N. Ishige, L. H. Pitts, L. Pogliani, et al., Neurosurgery, 20 (1987) 854.

14. L. Pogliani, T. L. James, F. Laschi, N. Ishige, L. H. Pitts, Phys.Med. 1 (1988) 13.

15. N. Ishige, F. Laschi, L. Pogliani, In Vivo, 3 (1989) 263

16. L. Pogliani, N. Ishige, In Vivo, 4 (1990) 191.

17. P. Plateau, C. Dumas, M. Gueron, J.Magn.Res. 54 (1983) 46.

18. B. Chance, S. Eleff, W. Bank, et al., Proc.Natl.Acad.Sci.USA, 79 (1982) 7714

19. J. R. Alger, K. L. Behar, D. L. Rothman, et al., J.Magn.Res. 56 (1984) 334

20. P. Canioni, J. R. Alger, R. G. Shulman, Biochemistry, 22 (1983) 4974

21. R. Damadian, Science, 171 (1971) 1151.

22. R. Damadian, H. Zaner, D. Hor, Physiol.Chem.Phys. 5 (1973) 381.

23. D. P. Hollis, L. A. Saryan, H. P. Morris, Johns Hopkins Med.J. 131 (1972) 441.

24. A. Saryan, D. P. Hollis, J. S. Economou, J.Natl.Cancer Inst. 52 (1974) 599

25. B. M. Fung, D. L. Durham, D. A. Wassil, Biochim.Biophys.Acta, 399 (1975) 191.

26. K. R. Foster, H. A. Resing, A. N. Garroway, Science, 194 (1976) 324.

27 P. T. Beall, R. M: Cailleau, C. F. Hazlewood, Physiol.Chem.Phys. 8 (1976) 281.

28. P. T. Beall, C. F. Hazlewood, P. N. Rao, Science, 192 (1976) 904

29. J. C. Egglestone, L. A. Saryan, D. P. Hollis, Cancer Res. 35 (1978) 1326.

30. P. T. Beall, et al., J.Natl.Cancer Inst. 64 (1980) 335.
31. P. C. Lauterbur, M. H. Mendonça-Dias, comunicação pessoal (1978).

32. J. A. Koutcher, M. Goldsmith, R. Damadian, Cancer, 41 (1978) 174.

33. D. P. Hollis, L. A. Saryan, J. C. Eggleston, H. P. Morris, J.Natl.Cancer Inst. 54 (1975) 1469.

34. S. R. Kasturi, S. S. Ranade, S. S. Shah, Proc. Indian Acad.Sci. 84B (1976) 60.

35. C. F. Hazlewood, G. Cleveland, D. Medina, J.Natl.Cancer Inst. 52 (1974) 1849

36. P. T. Beall, C. F. Hazlewood, Science 192 (1976) 904

37. P. Carver, Biophys. Soc. 13 (1973) 331a.

38. P. C. Lauterbur, Nature (London), 242 (1973) 190

39. J. Radon, Verh.Saechs.Akad.Wiss. 69 (1917) 262.

40. R. N. Bracewell, Aust.J.Phys. 9 (1956).

41. G. N. Hounsfield, Br.J.Radiol. 46 (1973) 1016

42. A. Kumar, I. Welti, R. R. Ernst, J.Magn.Res. 18 (1975) 69 .

43. H. T. Edzes, E. T. Samulski, Nature (London) 265 (1977) 521.

44. P.C. Lauterbur, NRM in Biology, R. A. Dwek et al., eds., Academic Press, New York, 1977.

45. A. Kumar, I. Welti, R. R. Ernst, Naturwissenschaften 62 (1975) 34

46. P. Brunner, R. R. Ernst, J.Magn. Res. 33 (1979) 83.

47. W. Hinshaw, J.Appl.Phys. 47 (1976) 3709.

48. J. M. S. Hutchinson, F. W. Smith, NRM Imaging in medicine, Igaku-Shoin, New York, 1981

49. W. A. Edelstein, M. S. Hutchinson, G. Johnson, T. W. Redpath, Phys.Med.Bio. 25 (1980) 751

50. A. Haase, J. Frahm, D. Matthei, W. Hanicke, K. D. Merboldt, J.Magn.Res. 67 (1986) 258.

51. P. Mansfield, J.Phys. C. Solid State Physics, 10 (1977) L55.

52. P. Mansfield, P. G. Morris, NRM Imaging in Biomedicine, supplement 2 of 'Advances in Magnetic Resonance, J. S. Waugh ed., Academic Press, New York, 1982

53. P. Mansfield et al. Phil. Trans, R.Soc.Lond. A333 (1990) 495.

54. G. Gatti, Chimicaoggi, novembre 1984, 25; marzo 1985, 29 .

55. Siemens AG, MAGNETON technical description.

56. E. L. Hahn, Phys.Rev. 80 (1950) 580.

57. H. Y. Carr, E. M. Purcell, Phys.Rev. 94 (1954) 630 .

58. F. E. Senftle, A. Thorpe, Nature (London) 190 (1961) 410. 

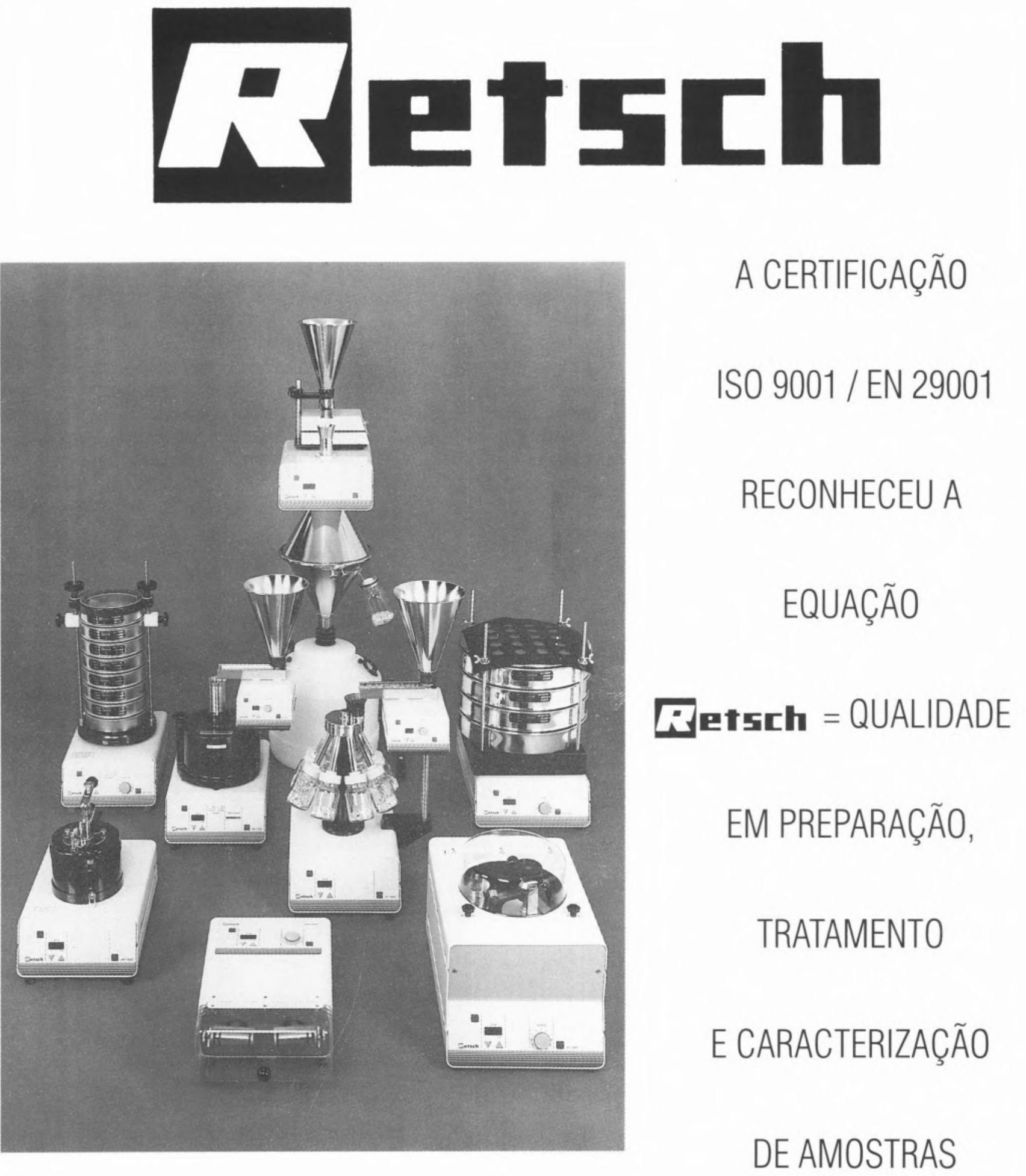

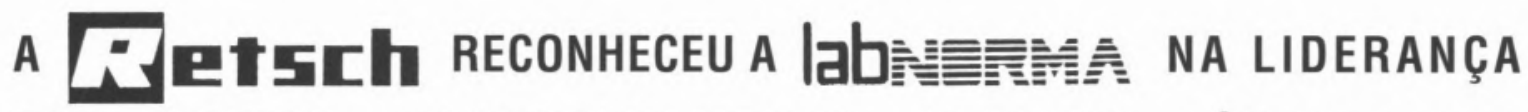
DAS VENDAS, ACONSELhamento, SERViçO PÓS-VEnda E ASSISTÊNCIA TÉCNICA AOS SEUS CLIENTES.

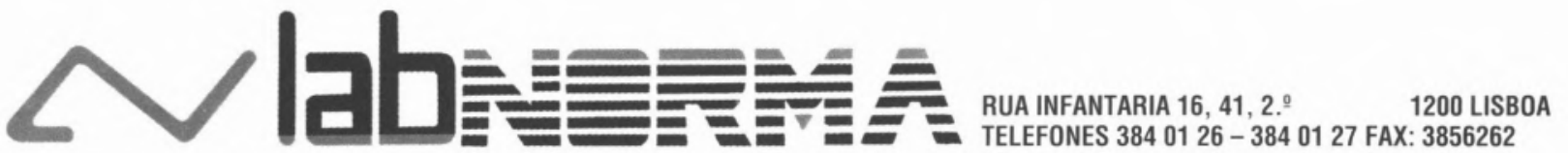

